\title{
Lower Extremity Claudication after Patent Foramen Ovale Closure
}

Sherri A Braksick ${ }^{1}$, Manju Kalra ${ }^{2}$ and James P Klaas ${ }^{1 *}$

${ }^{1}$ Department of Neurology, Mayo Clinic, Rochester, MN, USA

${ }^{2}$ Department of Vascular Surgery, Mayo Clinic, Rochester, MN, USA

*Corresponding author: James P. Klaas, 200 First St SW Rochester, MN 55905, Tel: (507) 266-3544; Fax: (507) 266-4419; E-mail: klaas.james@mayo.edu

Received date: February 19, 2015; Accepted date: March 14, 2015; Published date: March 18, 2015

Copyright: $\odot 2015$ Braksick SA. This is an open-access article distributed under the terms of the Creative Commons Attribution License, which permits unrestricted use, distribution, and reproduction in any medium, provided the original author and source are credited.

\section{Description}

A 42-year-old male presented to our facility for evaluation of lower extremity claudication with activity. His medical history was notable for a cortical stroke in the right middle cerebral artery territory at age 25 that had been attributed to a patent foramen ovale (PFO). At the time of the stroke he was prescribed aspirin and monitored. For unclear reasons, following an episode of chest pain many years later, an Amplatzer closure device was placed to close the known PFO. He had been an avid runner, with distances of 10-15 miles being common for him, but shortly after the procedure he began to develop symptoms of claudication, and was now unable to run more than 2-3 miles at a time. Evaluation at our institution revealed a foreign body, consistent with the Amplatzer device, in the distal aorta at the level of the iliac bifurcation (Figure 1). The device was removed (Figure 2) and his lower extremity symptoms resolved. PFO closure device migration is a rare complication, and lower extremity claudication has not previously been reported as a consequence of the procedure.

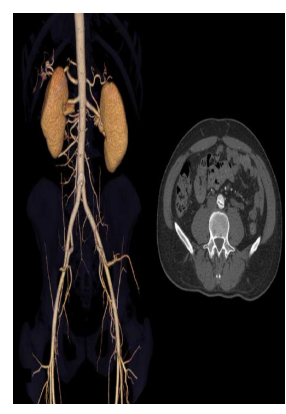

Figure 1

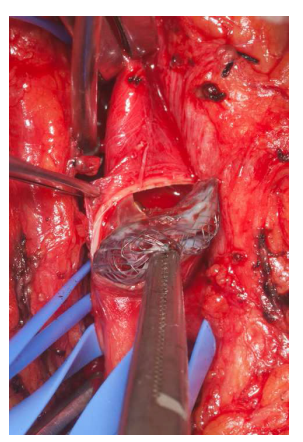

Figure 2 